Pacific Journal of Mathematics

A NOTE ON STARSHAPED SETS 


\title{
A NOTE ON STARSHAPED SETS
}

\author{
P. R. GOODEY
}

If $S$ is a compact subset of $R^{d}$, it is shown that $S$ is starshaped if and only if $S$ is nonseparating and the intersection of the stars of the $(d-2)$-extreme points of $S$ is nonempty.

Let $S \subset R^{d}$. The (d-2)-extreme points of $S$ are by definition those points of $S$ such that if $D \subset S$ is a (d-1)-dimensional simplex then $x \notin$ relint $D$ (the relative interior of $D$ ). The totality of $(d-2)$-extreme points of $S$ is denoted by $E(S)$. For each $y \in S$ we define $S(y)$, the star of $y$ by $S(y)=\{z:[y, z] \subset S\}$, where $[y, z]$ denotes the closed line segment from $y$ to $z$. $S$ is said to be starshaped if $\operatorname{Ker} S \neq \varnothing$ where $\operatorname{Ker} S=\{S(y): y \in S\}$. In [2] it is shown that if $S$ is a compact starshaped set in $R^{d}$ then $\operatorname{Ker} S=\bigcap\{S(y): y \in E(S)\}$. Thus the following question arises: if $S$ is such that $\bigcap\{S(y): y \in E(S)\} \neq \varnothing$, under what hypothesis is $S$ starshaped? It is clearly desirable that the hypothesis should be as weak as possible in order to indicate to what extent $\bigcap\{S(y): y \in E(S)\} \neq \varnothing$ implies that $S$ is starshaped. In [3] it is shown that one suitable hypothesis is that $S$ should have the halfray property, that is, for any point $x$ in $R^{d} \backslash S$ there is a half-line $l$ with vertex $x$ such that $l \cap S=\varnothing$. Now we note that this hypothesis is a rather strong one especially as it is being used to deduce the fact that a certain set is starshaped. Thus one suspects that a much weaker hypothesis might suffice. This suspicion is further strengthened by the example given in [3] to show that, in fact, some hypothesis is necessary. More precisely, the example given is a separating set that is, its complement is not connected. The purpose of this note is to prove the following

THEOREM. If $S \subset R^{d}$ is a nonseparating compact set and $\bigcap\{S(y): y \in E(S)\} \neq \varnothing$, then $S$ is starshaped.

Proof. Let $z \in \bigcap\{S(y): y \in E(S)\}$. We shall show that for any $x$ in $R^{d} \backslash S, l(x, z) \cap S=\varnothing$ where $l(x, z)$ is the half-line with vertex $x$ which does not contain $z$ but is such that the line containing $l(x, z)$ does contain $z$. Clearly this suffices to show that $S$ is starshaped.

Choose $x_{0}$ in the complement of the convex hull of $S$, then $l\left(x_{0}, z\right) \cap S=\varnothing$. Now since $S$ is a nonseparating compact set, its complement is a path-connected unbounded open set (see [1, p. 356]). Thus any point in $R^{d} \backslash S$ can be "joined" to $x_{0}$ by a finite polygonal path in $R^{d} \backslash s$ such that if $t$ is any segment of the path then the line 
containing $t$ does not contain $z$.

Now we assume $l(x, z) \cap S \neq \varnothing$ for some point $x$ in $R^{d} \backslash S$ and seek a contradiction. Let $P$ be a polygonal path as described above with consecutive vertices $v_{1}=x, v_{2}, v_{3}, \cdots, v_{n}=x_{0}$. Put $i=$ $\max \left\{j: l\left(v_{j}, z\right) \cap S \neq \varnothing\right\}$ then $1 \leqq i<n$. Let the closed segment $\left[v_{i}, v_{i+1}\right]$ be the image under the continuous function $f$ of the unit interval, with $f(0)=v_{i}$ and $f(1)=v_{i+1}$. Note that if $p \neq q$ then $l(f(p), z) \cap l(f(q), z)=\varnothing$. Now $l(f(1), z) \cap S=\varnothing$ and so, since $S$ is compact we can put $p=\max \{q: l(f(q), z) \cap S \neq \varnothing\}$ and then $0 \leqq p<1$. Let $y$ be the point of $S$ on $l(f(p), z)$ which is furthest from $z$. Now suppose $D$ is a $(d-1)$-simplex with $D \subset S$ and $y \in \operatorname{relint} D$.

Then $y$ must be the mid-point of a segment which is contained in $S \cap Q$ where $Q$ is the plane through $z, v_{i}, v_{i+1}$. But this is impossible because of the definition of $y$ and the fact that $l(f(q), z) \cap$ $S=\varnothing$ for $p<q \leqq 1$. Hence $y \in E(S)$ and so $f(p) \in S$. This contradiction shows that $l(x, z) \cap S=\varnothing$ and thus completes the proof.

Finally, as a result of the above theorem and the comments made in [2] we are led to ask: if $S$ has the half-ray property and has a point which "sees" just the extreme points of the convex hull of $S$ and not all the ( $d$-2)-extreme points, is $S$ necessarily starshaped? The following example shows that the answer is negative:

$$
S=\left\{(x, y) \in R^{2}:|x| \leqq 1,|y| \leqq 1\right\} \mid\left\{(x, y) \in R^{2}:|x|<\frac{1}{2} .|y|>\frac{1}{2}\right\} .
$$

Similarly we observe that if we rotate $S$ about the $y$-axis we obtain a three dimensional set with the required properties.

\section{REFERENCES}

1. J. Dugundji, Topology, Allyn and Bacon, Boston 1968.

2. J. W. Kenelly and W. R. Hare et al., Convex components, extreme points, and the convex kernel, Proc. Amer. Math. Soc., 21 (1969), 83-87.

3. N. Stavrakas, $A$ note on starshaped sets, (k)-extreme points and the half ray property, Pacific J. Math., 53 (1974), 627-628.

Received May 30, 1975, and in revised form July 4, 1975.

Royal Holloway College 


\section{PACIFIC JOURNAL OF MATHEMATICS}

\section{EDITORS}

RICHARD ARENS (Managing Editor) University of California

Los Angeles, California 90024

\section{R. A. BEAUMONT}

University of Washington Seattle, Washington 98105
J. DugundjI Department of Mathematics University of Southern Californı Los Angeles, California 90007

D. Gilbarg AND J. Milgram Stanford University Stanford, California 94305

\section{ASSOCIATE EDITORS}

E. F. BECKENBACH

B. H. NeUMANN

F. WOLF

K. YosHidA

\section{SUPPORTING INSTITUTIONS}

UNIVERSITY OF BRITISH COLUMBIA CALIFORNIA INSTITUTE OF TECHNOLOGY UNIVERSITY OF CALIFORNIA MONTANA STATE UNIVERSITY UNIVERSITY OF NEVADA NEW MEXICO STATE UNIVERSITY OREGON STATE UNIVERSITY UNIVERSITY OF OREGON OSAKA UNIVERSITY

\author{
UNIVERSITY OF SOUTHERN CALIFORNIA \\ STANFORD UNIVERSITY \\ UNIVERSITY OF TOKYO \\ UNIVERSITY OF UTAH \\ WASHINGTON STATE UNIVERSITY \\ UNIVERSITY OF WASHINGTON \\ AMERICAN MATHEMATICAL SOCIETY \\ NAVAL WEAPONS CENTER
}




\section{Pacific Journal of Mathematics}

\section{Vol. 61, No. $1 \quad$ November, 1975}

Jiří Adámek, V. Koubek and Věra Trnková, Sums of Boolean spaces represent every

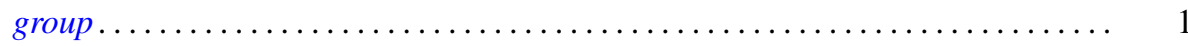

Richard Neal Ball, Full convex l-subgroups and the existence of $a^{*}$-closures of

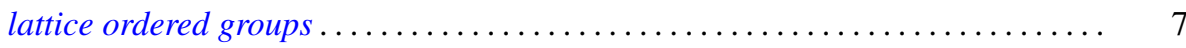

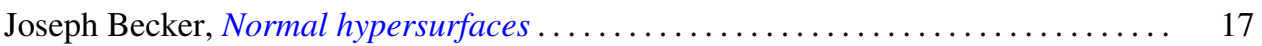

Gerald A. Beer, Starshaped sets and the Hausdorff metric . . . . . . . . . . . . . 21

Dennis Dale Berkey and Alan Cecil Lazer, Linear differential systems with

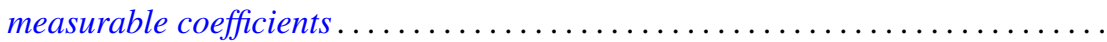

Harald Boehme, Glättungen von Abbildungen 3-dimensionaler

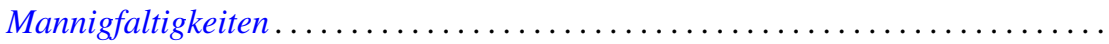

Stephen LaVern Campbell, Linear operators for which $T^{*} T$ and $T+T^{*}$

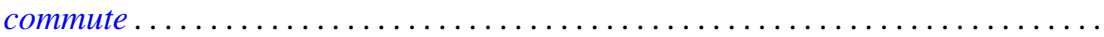

H. P. Dikshit and Arun Kumar, Absolute summability of Fourier series with

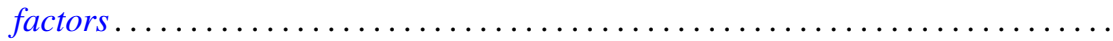

Andrew George Earnest and John Sollion Hsia, Spinor norms of local integral

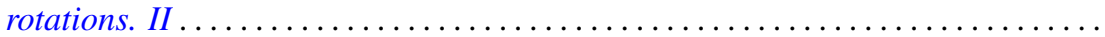

Erik Maurice Ellentuck, Semigroups, Horn sentences and isolic structures .........

Ingrid Fotino, Generalized convolution ring of arithmetic functions . . . . . . . . . . .

Michael Randy Gabel, Lower bounds on the stable range of polynomial rings .......

Fergus John Gaines, Kato-Taussky-Wielandt commutator relations and

characteristic curves

Theodore William Gamelin, The polynomial hulls of certain subsets of $C^{2}$

R. J. Gazik and Darrell Conley Kent, Coarse uniform convergence spaces. . .

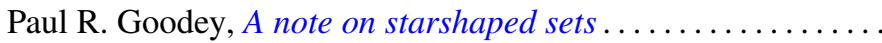

Eloise A. Hamann, On power-invariance

M. Jayachandran and M. Rajagopalan, Scattered compactification for $N \cup\{P\}$. . .

V. Karunakaran, Certain classes of regular univalent functions .

John Cronan Kieffer, A ratio limit theorem for a strongly subadditive set function in a locally compact amenable group .................

Siu Kwong Lo and Harald G. Niederreiter, Banach-Buck measure, density, and uniform distribution in rings of algebraic integers ........

Harold W. Martin, Contractibility of topological spaces onto metric spaces ....

Harold W. Martin, Local connectedness in developable spaces .

A. Meir and John W. Moon, Relations between packing and covering numbers of a tree.

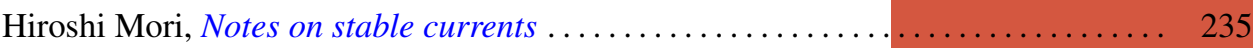

Donald J. Newman and I. J. Schoenberg, Splines and the logarithmic function . . . . 241

M. Ann Piech, Locality of the number of particles operator....

Fred Richman, The constructive theory of $K T$-modules .......

Gerard Sierksma, Carathéodory and Helly-numbers of

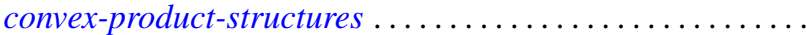

Raymond Earl Smithson, Subcontinuity for multifunctions .... . . 